\title{
GRUPO YUYACHKANI: PEDAGOGIA E MEMÓRIA
}

\author{
Narciso Telles ${ }^{2}$
}

\section{Resumo}

O presente artigo apresenta reflexões em torno da pedagogia do teatro desenvolvida pelo Grupo Yuyachkani (Peru) a partir da experiência do autor no laboratório pedagógico organizado pelo Grupo em fevereiro de 2001.

Palavras-chave: pedagogia do teatro, teatro latino americano, Grupo Yuyachkani.

Abstract

This article presents reflections on the pedagogy of theater developed by Yuyachkani Group (Peru) from the author's experience teaching in the laboratory organized by the Group in February 2001.

Keywords: theater pedagogy, Latin American theater, Group Yuyachkani. 


\section{Fevereiro do ano lunar de 2011}

ais uma vez estou
de frente ao alto
muro vermelho e
uma imensa porta
de madeira de cor verde que separa dois mundos: o real presentificado na arquitetura e práticas sociais do bairro de Madgalena Del Mar, Lima, Peru e o artístico quando adentramos a Casa Yuyachkani e re-encontramos uma História/Memória de um grupo teatral comemorando seus 41 anos de existência.

Reconheço em minha memória-corpo a primeira vez que estive ali:

O contato com o Grupo Cultural Yuyachkani ocorreu no período de 26 de julho a 1 de agosto de 2004, quando fui aceito como aluno no curso Theatre/Memory/Politics: workshop in Peru $^{2}$,oferecido aos alunos de pósgraduação do Instituto Hemisférico de Performance e Política das Américas.

Agora, passados 7 anos, volto à Casa, que Oxumaré nos proteja, para participar do laboratório pedagógico oferecido pelo Grupo.

Segundo a etimologia, laboratório:

1. Local para elaboração ou análise de produtos, experiências ou exames científicos. 2. Local para revelação, ampliação etc de fotografias (Houaiss).

2. Sala ou edifício onde se fazem experiências científicas, exames e/ou preparo de medicamentos, exames clínicos, fabricação de explosivos etc. (Aurélio)

No campo teatral temos:

Antonio Januzelli define o laboratório dramático como o "conjunto de práticas que o ator deve desencadear para: a)

1 Ator, performer, diretor e professor do Curso de Teatro e do Programa de Pós-Graduação em Artes da Universidade Federal de Uberlândia (UFU). Pesquisador do CNPq e membro do Coletivo Teatro da Margem (Uberlândia/MG).

2 Cf. hemi.nyu.edu/course-nyu/yuya afinar e aprimorar seu equipamento de trabalho, b) aprofundar-se no conhecimento orgânico de seu papel" (JANUZELLI, 1986, 49).

A noção de laboratório experimental apresentada pela professora Beti Rabetti é a seguinte: fundamentalmente realimentar o campo das reflexões destinadas a estudar e compreender objetos coletados em campo artístico, gerando momentos de entrada nesses objetos, experimentando algumas de suas partes, num caminho que articula também, como se pode ver, a análise e a síntese, o todo e as partes (RABETTI In: CARREIRA; CABRAL; RAMOS; FARIAS, 2006, p. 55 - 56).

Para esta reflexão propomos pensar os processos de criação, pesquisa ou ensinoaprendizagem pelo saber da experiência, que passa pela singularidade do sujeito que nela está inserido, diferentemente da lógica do experimento que produz acordo ou homogeneidade entre os sujeitos, a experiência se localiza na diferença e na pluralidade. Desta forma, aqui tratamos de um olhar singular sobre a prática pedagógica do Yuyachkani, circunscrevendo-a no panorama latino-americano e utilizando tintas auto-etnográficas.

\section{Yuyachkani, para que a memória floresça}

O Grupo Cultural Yuyachkani surgiu em 1971 com uma atitude de fortalecer a relação entre $o$ teatro peruano e a história de seu país. Os atores do grupo Ana Correa e Augusto Casafranca comentavam esta primeira fase do grupo: "No queríamos hacer um teatro tradicional ni um teatro que se divorciara de la realidad" (1994). Nesta etapa, uma das grandes referências era a obra e o pensamento de Bertolt Brecht.

No início dos anos de 1980, o grupo busca um maior equilíbrio entre forma e conteúdo e uma definição sobre o trabalho de ator que desenvolvem e que desejariam desenvolver. A preocupação a partir deste momento estava centrada na 
questão da atuação e tinha relação direta com o Encontro com Eugenio Barba e o Odin Teatret em 1978.

A presença e a influência do pensamento-prática de Eugenio Barba na América Latina é algo inegável. Vários são os grupos e artistas nos diversos países do continente que trabalham a partir dos preceitos da antropologia teatral. Ian Watson (1993) revela que Brecht, Grotovski e Barba são os três teatrólogos europeus que mais influência têm na produção teatral latino-americana. Porém, diferente de seus precedentes, Barba e o Odin têm sua relação fortemente alicerçada por seguidas vindas à região, desde os anos de 1970 e, a partir dos anos de 1980, quase ininterruptamente, participando de seminários, festivais, oficinas, seções e demonstrações de trabalho, a convite de grupos e instituições culturais (MASGRAU In: BARBA, 2002, p. 74).

Esta presença constante dinamiza o conhecimento e os métodos de trabalho e "treinamento" do grupo. O Yuyachkani teve seu primeiro contato com o Odin, no ano de 1978, quando o mesmo participava do Encontro de Teatro de Grupo em Ayacucho, organizado pelo grupo Cuatrotablas. O impacto foi intenso como comenta Miguel Rubio:

El "Encuentro de Aycucho" a pesar de todas as objeciones y rechazos, había creado hilos conductores de una corriente invisible que sentíamos com mucha forza, la central de energia venía del infatigable trabajo del Odin en las calles, en las comunidades campesinas y mercados, propiciando trueques, ellos llegaban a un lugar previamente establecido, presentaban su trabajo y luego la comunidad le respondía también con un trabajo artístico. En estos encuentros se verbalizaba poco, esto potenciaba otros niveles de la comunicación que van más allá de las palabras, lo asombroso era ver el nivel de respuesta que se establecía al ponerse el grupo de igual a igual con la comunidad, plateandoelintercambiocomo base antes que la prédica o paternalismo en el que - ahora hay reconocerlo - caímos muchos de los que llevábamos al pueblo las "ideas correctas". Ésta es una lección de la que me siento agradecido porque fue muy útil para repensar nuestros estilos (ZAPATA, 2001, p. 146).

O comentário de Rubio pontua a mudança de rumo, no campo do trabalho atorial, ocorrido no Yuyachkani a partir de então. De um teatro, cujo foco estava centrado no ator-militante, ou seja, um ator que compreende criticamente seu meio social e utiliza a palavra como instrumento teatral de percepção e discussão do mundo, passa à compreensão de um ator que percebe e trabalha, a partir de seus referenciais culturais, seus canais psicofísicos na construção de uma dramaturgia própria, por um procedimento de "treinamento" contínuo. A concepção do exercício e do ofício atorial ganha uma maior complexidade sem perder de vista seu posicionamento e sua função social.

Ao longo dos anos o contato com o Odin foi se ampliando em diversas idas e vindas do grupo a Lima e com a participação de Rubio e dos atores do Yuyachkani nas sessões da ISTA (Internacional School of Theatre Anthropology).

Identificamos, principalmente, três aspectos na pedagogia do Yuyachkani que tem profunda relação com a influência/ referência do Odin: o "treinamento"; a troca para a constituição de repertórios atoriais e "aprender a aprender" improvisação e autonomia como método de criação atorial.

O termo treinamento aparece como um componente estrutural nas diversas pedagogias do ator surgidas na Europa e América do Norte no decorrer do século passado. Sua noção está atrelada "à noção de exercício e aperfeiçoamento" (FÉRAL, 2003, p. 49) do instrumento ator por meio de um conjunto de atividades realizadas com certa freqüência. Este entendimento foi amplamente disseminado pelos livros de Grotowski, Barba, Brook, Oida e ecoou pelos países latino-americanos e nos jovens agrupamentos teatrais contemporâneos.

Com isto, a concepção de treinamento vai-se configurando a partir de alguns fundamentos: a)a formação passa pela 
relação mestre-discípulo; b)a técnica não deve ser um fim em si; c) aprende-se ao longo de uma trajetória; d) o aprendizado passa a ser individualizado.

A ideia da formação artística pela via, relação mestre-discípulo, é colocada como uma outra via, não-fragmentada ou pluralizada, às escolas formais de ensino teatral. A aquisição do conhecimento ocorre mediante o encontro - em tempo reduzido - com um conjunto de professores com modos de fazer e ensinar teatro distintos. $\mathrm{O}$ ensinamento via mestre ocorre de maneira contínua, profunda e está vinculado a um único entendimento de fazer/ensinar teatro. "O teatro como escola, a companhia teatral como lugar de formação, a escola como vinculada a um teatro" (Ibidem, p. 52).

Aqui também a técnica passa a ser vista como um processo facilitador para a criação atorial, um meio do qual o ator dispõe para seu trabalho. Nega-se a ideia de um atoratleta ou virtuoso, onde a técnica aparece como algo preponderante. É na superação deste modelo que o treinamento se coloca.

No treinamento, a aquisição e a construção do conhecimento teatral estão relacionadas também ao conhecimento que o ator tem sobre si próprio. "O verdadeiro treinamento continua pela vida toda" (Ibid., p. 54). A ênfase está localizada no sentido processual que o trabalho diário pode produzir e é justamente esta regularidade que afina e prepara o instrumento do ator, suas capacidades psicofísicas.

Nesta proposta, a individualização do treinamento é o caminho definidor do aprimoramento atorial. Ao investir sua pessoalidade neste processo, o ator ao longo do tempo adquire uma maior consciência de si, no processo, na relação com os outros atores, na sua forma de jogo e nos seus limites. Para Féral, este movimento de individualização separou o treinamento do processo pedagógico (Ibid., p. 55). Porém, pensamos que o que ocorre não seja uma separação, mas uma outra proposta pedagógica, uma nova forma de relação ensino-aprendizagem, na qual a responsabilidade sobre a aquisição do conhecimento teatral passa a ser mais do ator e de seu investimento no processo de trabalho do que propriamente da dinâmica inscrita pelo professor e/ou mestre. Passase a assumir uma concepção de didática do teatro calcada na ideia "aprender a aprender". O aluno passa a ser percebido não como uma figura passiva no processo de ensino-aprendizagem, mas como um agente responsável por sua formação. Neste sentido o processo pedagógico, no âmbito teatral, pode ser compreendido pela relação estabelecida entre o educador e o educando, que, segundo Paulo Freire, promove um diálogo entre conhecimentos de todos os envolvidos no processo, e não pressupõe o aluno como uma "folha em branco" a ser preenchida peloconhecimento do professor. Do mesmo modo, a didática teatral deve compreender que o aluno em seu processo formativo necessita adquirir a percepção de sua função e responsabilidade na aquisição de novos conhecimentos.

Para Barba (1997), instaura-se um processo pedagógico, que se nega a si mesmo enquanto algo cristalizador, de uma verdade inerte e imutável. Ao contrário, o pedagógico se encontra na dinâmica de um aprendizado contínuo, rebelde, baseado na troca de experiências teatrais diversas que propiciam a cada participante envolvido descobrir novas possibilidades de criação.

A proposta pedagógica da Antropologia Teatral fundamenta-se na pré-expressividade, nos "princípios-queretornam" encontrados em diferentes técnicas extra-cotidianas de atores de diversos tempos e culturas. Tais princípios estarão relacionados, por exemplo, ao equilíbrio, ao uso dos olhos e da coluna vertebral, ao peso.

É juntamente por este aspecto que aparece a opção didática pela improvisação como um procedimento de trabalho que alarga as possibilidades criativas do ator. Diferente da improvisação na criação coletiva, nesta didática ela é trabalhada, em primeira instância, no indivíduo, para que este "descubra" e desenvolva seu estado 
performativo. É importante mencionar que todos os elementos constituintes da pré-expressividade - momento designado pela antropologia teatral como anterior ao processo de construção de personagem, que visa desenvolver elementos estruturais do instrumento atorial-, citados anteriormente, constituem-se partes deste processo e instrumentalizam o ator para a construção de ações físicas, aquisição de precisão e presença cênica, variação rítmica e trabalho com objetos.

Um terceiro ponto de influência/ referência é o que chamamos de "troca para a constituição de repertórios atoriais". Quando Barba apresenta a ideia do Terceiro Teatro, como aquele que germina e cresce fora das regras do mercado teatral com um forte vínculo com as identidades culturais, ele aparece, subjacente a esta noção de permuta: A atua para B e B atua para A. Esta relação de troca entre grupos e/ou entre culturas direciona e determina a constituição teórico-prática da antropologia teatral. Segundo Ian Watson (2000),

el trueque se ha transformado en moneda corriente en el Terceiro Teatro. Grupos como el Potlach y el Tascabile di Bergamo en Itália. Cuatrotablas y Yuyachkani em Perú y Teatro Libre y Teatro Núcleo en la Argentina han seguido el liderazgo de Barba en el uso de la actuación como punto de contacto entre diferentes culturas (p. 49).

As formas de contato com outras culturas, sejam elas internas na tensão de identidades que formam um determinado país ou externas, entre culturas e práticas bastante distintas, constituíram os fundamentos para a elaboração por Barba dos "príncípiosque-retornam" como um conjunto de elementos - jogo de oposições, equilíbrio precário, fragmentações de partes do corpo, estado de prontidão, impulso, força - que são identificados nestas diferentes culturas e se revelam, numa operação de bricolagem, frutíferos para o desenvolvimento de um modelo de ator.
A prática teatralem ruas comoexercício investigativo deuma teatralidade, útiltanto na cena quanto no exercício técnico atorial em espaços abertos, aliada ao contato e à influência da antropologia teatral, demarca o campo de ação pedagógica que os atores do Yuyachkani intensificam no decorrer nos anos 90.

Estas experiências são fundamentais para a constituição do eixo caracterizador da pedagogia do Yuyachkani: o conceito de ator múltiplo. A experiência do grupo com espetáculos de rua e em espaços alternativos levou à formulação de um conjunto de conhecimentos que o ator deva aprender e desenvolver em seu trabalho. A respeito do ator-múltiplo, registramos as seguintes palavras de Ana Correa:

\begin{abstract}
Nos anos 80 [do século XX] que falamos da atriz e do ator múltiplo, porque tem que dominar o espaço de fora [da rua]. Este ator que faz de tudo: que é capaz de bailar, usar máscaras, pernas de pau, tocar instrumentos [...] Porque você é quem conquista a atenção de um espectador, que, necessariamente, veio para te ver. Você tem que namorá-lo, que capturá-lo. ${ }^{3}$
\end{abstract}

Para Miguel Rubio é fundamental que "o ator busque uma técnica [ou diversas] adequada a esta necessidade e ao mesmo tempo desenvolva um especial sentido de observação que o faça estar atento e sensibilizado para as diversas trocas com o público" (ZAPATA, 2001. p.34).

A concepção sobre o instrumento-ator e seu papel social vai, conseqüentemente, fundamentar a forma didática nas oficinas que o grupo ministra em sua sede, festivais e eventos ao longo dos anos.

Tal intensidade de atividades gerou a produção de uma grande quantidade de material documental sobre o trabalho pedagógico do grupo, inclusive já publicado. Aliado a isto, durante nossa pesquisa, filmamos diversos momentos

3 Entrevista realizada por Narciso Telles com Ana Correa. Lima, 2004. 
da oficina de Ana Correa, além de uma entrevista aberta com ela para uma análise mais detalhada de seu processo didático que revela concepções e práticas compartilhadas por outros atores do Yuyachkani, ou como nos disse Ana:

esse mesmo princípio se é ensinado por Teresa vai ser do ponto de vista de Teresa, se é ensinado por Augusto será do ponto de vista de Augusto. Isso é bom e maravilhoso. Tratamos de pegar esta diversidade pluricultural no Yuyachkani. ${ }^{4}$

Pela fala fica claro que existe uma identificação dos atores com o projeto teatral do Yuyachkani, o que nos permite analisar uma determinada oficina e tecer comentários sobre caminhos pedagógicos que norteiam o projeto grupal ao longo de seus 41 anos de atividade.

Sete anos se passaram desde que estive ali pela primeira vez. A memória do primeiro momento que tomei contato com as obras e as práticas pedagógicas do Yuyachkani toma meu corpo e me faz (re)pensar o como fazemos/ ensinamos/aprendemos pedagogia(s) do teatro. Qual o envolvimento ou distanciamento que temos que ter diante dos sujeitos ou objetos em estudo? Novamente me aproximo do pensamento de Larossa quando menciona que o sujeito da experiência é como uma "superfície de sensibilidade na qual aquilo que passa afeta de algum modo, produz alguns afetos, inscreve algumas marcas, deixa alguns vestígios, alguns efeitos" (2004, p.160)

Relacionando pedagogia e memória e tendo a experiência como uma atitude metodológica, adentro ao Laboratório Pedagógico do Yuyachkani, para compreender que estas práticas são cruzamentos de caminhos entre arte e vida.

O laboratório pedagógico foi criado como uma necessidade do grupo de ter um espaço de compartilhamento de

4 Entrevista realizada por Narciso Telles com Ana Correa. Lima, 2004. suas questões e conhecimentos artísticos adquiridos ao longo de sua trajetória com outros artistas.

Este ideário de compartilhamento entre grupos na América Latina tem sua origem na experiência da Escola Internacional da América Latina e Caribe (EITALC), criada em Havana durante o Encontro de Teatro da América Latina e Caribe, organizado pela Casa de Las Américas em 1987, esta escola itinerante de formação teatral. Seus 'talleres' que ocorreram inicialmente em Cuba e depois percorreram diversos países latinoamericanos, tinham como proposta o ensino do teatro a partir da experiência e da vivência dos participantes com o projeto poético/técnico de cada grupo/ artista que coordenava os 'talleres' daquele ano. Reunir pessoas em torno de um projeto de trabalho específico de modo a compartilhar e problematizar das práticas de trabalho realizadas na América Latina naquele momento.

$\mathrm{Na}$ sua estrutura o Laboratório é organizado em diversas atividades: assistência de espetáculos, desmontagens, oficinas, conferências, rodas de conversas e o Pátio de contatos. Em seus princípios vê-se a memória histórica e social como fonte de investigação. Tanto nas obras apresentadas aos participantes, como nos temas mobilizadores das oficinas e socializados no pátio de contatos a memória latino-americana aparece como a

(...) necessidade de se apreender a memória ao mesmo tempo como reconstrução-evocação e irrupção, ao mesmo tempo consciência e emoção; com existência fora edentro(inclusivedeforma inconsciente, recalcada) dos indivíduos e grupos sociais e constituindo-se como fator essencial da constituição das subjetividades" (SEIXAS, 2001, p. 105).

Reconhecer-se como artista (ser político), compreender que a aquisição de conhecimentos técnicos pressupõe um compromisso ético com a história de seu país, entender o teatro como uma arte capaz 
de evocar as subjetividades da memória para a criação e fazer-pensar práticas pedagógicas que acionem na experiência a possibilidade de um conhecimento sensível são pontos que constituem o Laboratório Pedagógico do Yuyachkani.

\section{Junho do ano lunar de 2011}

\section{Referências bibliográficas}

BARBA, Eugenio. Teatro: soledad, oficio y revuelta. Buenos Aires: Catálogos, 1997.

$$
\text { Arar el Cielo. Diálogos }
$$

latinoamericanos. Havana: Casa de las Américas, 2002.

CARREIRA, André; CABRAL, Biange; RAMOS, Luiz Fernando; FARIAS, Sérgio Coelho (orgs.) Metodologias de pesquisa em Artes Cênicas. Rio de Janeiro: 7 Letras, 2006. FÉRAL, Josette. Vous avez dit "training? O Teatro Transcende, Blumenau, n.12, p. $49-58,2003$. [tradução e notas de José Ronaldo Faleiro] (coord). L'école du jeu. Saint-Jeande-Védas:L'Entretemps, 2003.

JANUZELLI, Antonio. A aprendizagem do ator. São Paulo: Ática, 1986.

LARROSA, Jorge. Linguagem e educação depois de Babel. Belo Horizonte: Autêntica, 2004. SEIXAS, Jacy Alves de. Halbwachs e a memória-reconstrução do passado. História. UNESP - São Paulo, n. 20, p. 93 - 108, 2001. TELLES, Narciso. Pedagogia do teatro e o teatro de rua. Porto Alegre: Mediação, 2008.

WATSON, Ian. Hacia un tercer teatro: Eugenio Barba y el Odin Teatret. Ciudad Real: Ñaque Editora, 2000.

ZAPATA, Miguel Rubio. Notas sobre Teatro. Lima: Ediciones Grupo Cultural Yuyachkani, 2001. 